(RESEARCH ARTICLE)

\title{
Bio efficacy of corm extract of Arisaema murrayi against mosquito larvae
}

\author{
Kad Aishwarya ${ }^{1}$ and Jagtap Shilpa Mahesh ${ }^{2}$ \\ ${ }^{1}$ Department of Zoology Hutatma Rajguru Mahavidyala, Rajgurunagar. \\ ${ }^{2}$ Department of Botany, Sahebraoji Buttepatil Mahavidyala, Rajgurunagar (MS) India.
}

Publication history: Received on 27 November 2019; revised on 09 December 2019; accepted on 17 December 2019

Article DOI: https://doi.org/10.30574/wjarr.2019.4.2.0096

\begin{abstract}
Arisaema murrayi (sapkanda) is an ancient plant used as food and medicine for many diseases by tribal people. The present study was undertaken to investigate the larvicidal properties of corm extract of Arisaema murrayi, against mosquito larvae. The larvae were exposed to a solution prepared from corm extract powder in ethanol. Mortality was assessed within 4-6 hrs. The result indicated that the corm extract has toxic effect on mosquito larvae and therefore has potential for development as commercial bio-insecticide.
\end{abstract}

Keywords: Arisaema murrayi; Mosquito Larvae; Bio-insecticide

\section{Introduction}

Dengue, malaria and chikungunya struck over 1.13 million people in the country last year. Of these, 766 succumbed. India bears a huge burden of mosquito-borne diseases, contributing 34 per cent of global dengue and 11 per cent of global malaria cases. Insect-borne diseases cause significant human poor health and Death. Current control and preventive methods against vector-borne diseases rely mainly on insecticides. The emergence of insecticide resistance in many disease vectors highlights the necessity to develop new strategies to control these insects $[1,2]$.

Vector-control strategies in the last century were based on chemical agents such as dichloro-diphenyl-trichloroethane (DDT) [3]. Although insecticides have been successfully used to control mosquitoes of the genera Aedes and Anopheles, current ecological and environmental protection standards do not allow such approaches because of the adverse effects of many insecticides on non-target species, including humans, their environmental impact, the contamination of soil and water and the development of selective processes and subsequent mosquito resistance to insecticides [4]. Azadirachta indica, Neem extract (biopesticide) is an effective insecticide against the insect pests [5,6]. Botanical pesticides exert a range of behavioral and physiological effects on the colonization, development, growth survival and multiplication of insects [7]. The Azadirachta indica, Vitex negundo and Partheneum histerophorus are the medicinal plants and plays insecticidal role. Azadirachta indica and Partheneum histerophorus plant extracts are also efficient against the scarab beetles. These both biopesticides are higher efficiency occurred. Azadirachta indica and Partheneum histerophorus plays an important role in insecticides [8].

Arisaema murrayi (sapkanda) is an ancient plant used as food and medicine for many diseases by tribal people. Corm and leaf is reported moderately poisonous. Its ingestion may cause vomiting in animal. So these property of this medicinal plant can use to control growth of mosquito.

The genus Arisama C. Martius represented by about 170 species distributed almost throughout the world. In India there are 43 species and 9 varieties distributed in the Himalaya and Western Ghats. In Maharashtra, the genus Arisaema (Species - Arisaema murrayi Common name: Murray's Cobra Lily is represented by 7 species. Murray's Cobra Lily is a species of Cobra Lily found in the Western Ghats. It is a tuberous herb, 30-50 cm high. A single leaf, with 5-7 leaflets,

\footnotetext{
${ }^{*}$ Corresponding author

E-mail address: aishwaryakad93@gmail.com
}

Copyright (C) 2019 Author(s) retain the copyright of this article. This article is published under the terms of the Creative Commons Attribution Liscense 4.0. 
comes out after the flowers. The inflorescence is typical of the cobra lily plants. The spathe (or the "hood") is 5-15 cm, forming wide tube at the base; the upper part of the spathe is white with purple base. The lower part is green. A deep purple threadlike appendage comes out from the spadix. It is curved and protrudes out of the "hood". Minute flowers reside on the spadix, covered by the spathe [9].

The present study was carried out to evaluate bio efficacy of mosquito derived from Bio-insecticide. An attempt has been made to develop a Bio-insecticide which is more effective, cheap and non- hazardous to the environment pleasant and health friendly using different binders.

Arisaem amurrayi (sapkanda) is an ancient plant used as food and medicine for many diseases by tribal people. To observe larvicidal activity of Arisaema murrayi (sapkanda) corm extract.

\section{Material andmethods}

Arisaema murrayi (sapkanda) corm sundried for 3-5 days. Sundried corm grinded to make powder .5gm of powder mix in $200 \mathrm{ml}$ ethanol and boiled up to ethanol evaporate. After evaporation of ethanol residue was applied on mosquito larvae. After application of this extract larvae died within 4 hrs (Figure 1).

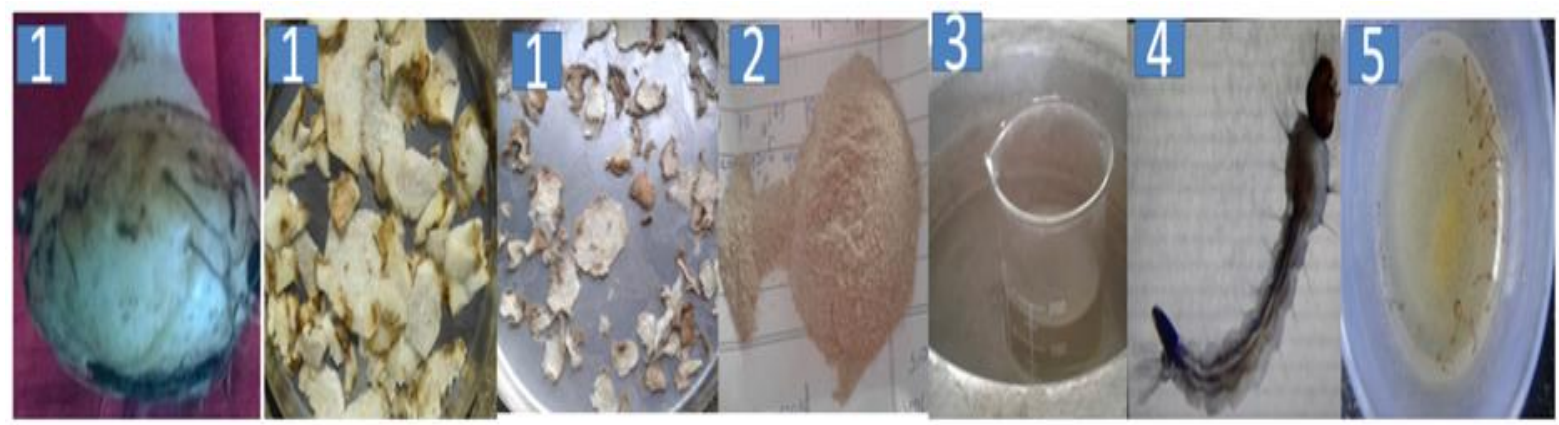

Figure 1 Photograph showing different stages in methods of extraction and application of corm powder extract

\section{Results}

The bio-efficacy of four different solutions of corm of Arisaema murrayi (sapkanda) on mosquito was showed about $40 \%, 57 \%, 71 \%$ and $100 \%$ death of mosquito larvae was observed in 48 hrs and 51\%, 86\%, !00\%, 10\% death of mosquito larvae was observed in $72 \mathrm{hrs}$ respectively (Table 1, figure 2 ). All four solutions were showed death of larvae in 48 and 72 hrs but $0.02 \%$ solution shows $100 \%$ death of mosquito larvae. Mortality was assessed within $48-72$ hrs there may be some secondary metabolites are present which are poisonous to these mosquito larvae. These secondary metabolites need to be analyzed.

Table 1 Table showing Effect of Corm extract powder and mortality duration of Mosquito larvae

\begin{tabular}{|c|c|c|c|c|c|c|}
\hline \multirow[t]{3}{*}{ Test } & \multirow{3}{*}{$\begin{array}{l}\text { Conc. of corm } \\
\mathrm{mg} / \mathrm{L}\end{array}$} & \multirow[t]{3}{*}{ Powder } & \multicolumn{4}{|c|}{ Mortality Duration } \\
\hline & & & \multicolumn{2}{|c|}{$48 \mathrm{hrs}$} & \multicolumn{2}{|c|}{$72 \mathrm{hrs}$} \\
\hline & & & Number & $\%$ & Number & $\%$ \\
\hline 50 & control & & 0 & - & 0 & - \\
\hline 50 & 0.005 & & 28 & 40 & 36 & 51 \\
\hline 50 & 0.01 & & 40 & 57 & 60 & 86 \\
\hline 50 & 0.015 & & 52 & 71 & 70 & 100 \\
\hline 50 & 0.02 & & 70 & 100 & 70 & 100 \\
\hline
\end{tabular}




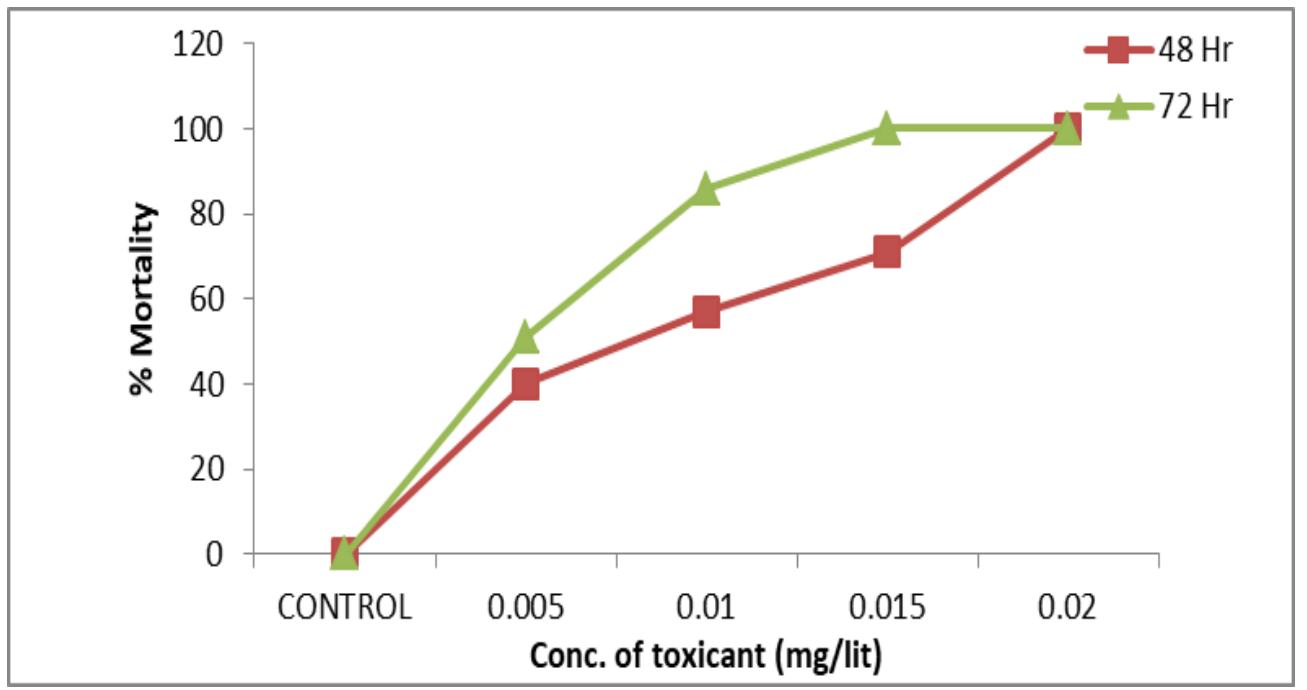

Figure 2 Showing effect of corm extract powder and mortality duration of Mosquito larvae

\section{Conclusion}

The result indicated that the corm extract has toxic effect on mosquito larvae and therefore has the potential for development as commercial bio-insecticide. This Bio-insecticide will be eco-friendly.

\section{Compliance with ethical standards}

\section{Acknowledgments}

We are thankful to Dr. S B Patil, HOD. Dept of Zoology, Hutatma Rajguru Mahavidyalaya for his timely help and support.

\section{Disclosure of conflict of interest}

Authors declare no conflict of interest exist.

\section{References}

[1] Duguma D, Ortiz SL, Lin Y, Wilson PC and Walton WE. [2017]. Effects of a larval mosquito biopesticide and Culex larvae on a fresh water nanophytoplankton (Selenastrum capricornatum) under axenic conditions, 42(1), 51-59.

[2] Iliano V, Coutinho-Abreu, Kun Yan Zhu and Marcelo Ramalho-Ortigao. [2010]. Transgenesis and paratransgenesis to control insect-borne diseases. Current status and future challenges Parasitology International, 59, 1-8.

[3] André Barretto Bruno Wilke and Mauro Toledo Marrelli. [2015]. Paratransgenesis: a promising new strategy for mosquito vector control. Parasites \& Vectors volume 8, 342.

[4] Dorta DM, Vasuki V and Rajavel A. [1993].Evaluation of organophosphorus and synthetic pyrethroid insecticides against six vector mosquito species. Rev Saude Publica, 27,391-7.

[5] Baidoo PK, Adam JI and Sarpong- Nsiah M. (2006). The role of extracts of Azadirachta indica and Lentana camara (L) in the reduction of damage done to maize plants by Lepidopterous stem- borers. International Journal of Food and Agricultural Research, b 3, 66-70.

[6] Schmutter H. (1990). Properties and potentials of natural pesticides from the neem trees. Annual review of Entomology, 35, 271- 298.

[7] Anonymous GR. (2008). U. S. Congress, Office of Technology assessment, biologically Anonymous. Package of practices for Kharif crops of Punjab. Punjab Agricultural University, Ludhiana, India Journal of Pacific Entomology, 2, 61-67. 
[8] Theurkar SV and Patil SB. [2012]. Effect of different Biopesticides on fecundity and Egg hatchability of Holotrichia fissa, Holotrichia serrata and Leucopholis lepidophora (Coleoptera: Scarabaeidae). International Journal of Advance Research in Engineering and Applied Sciences, 1, 1-7.

\section{How to cite this article}

Kad A and Jagtap S.M. (2019). Bio efficacy of corm extract of Arisaema murrayi against mosquito larvae. World Journal of Advanced Research and Reviews, 4(2), 39-42. 